\title{
Advice to the Philosophically Perplexed: a Reply to Saladin Meckled-Garcia's booknote on Escape from Leviathan
}

\section{J. C. LESTER}

Despite receiving high praise from Professors Barry, Narveson, Flew, and Gray (see the first page of the paperback), the Saladin Meckled-Garcia review (M-G) puts the level of Escape from Leviathan (EFL) as "undergraduate" and rates it one star. ${ }^{1}$ While undergraduates may profit from reading $E F L$, it is not mainly at their level. M-G either applies unusually high standards of philosophical argumentation or is simply philosophically perplexed.

It is hard to answer the charge that libertarian thought is "implausible" when no examples or arguments are given. To use and defend relevant theories of rationality, liberty, welfare, and anarchy is not "ingeniously redefining key terms". Theories, not definitions, are important, as Karl Popper rightly saw and as I agreed with in the book's introduction (3). And these theories are defended as being independently plausible rather than merely compatible in an ad hoc way.

No argument is given as to why an apriorist theory of instrumental rationality cannot legitimately and usefully embrace "desire, value and reason for action" (as I argue it can, at length) and thereby allow for economic analysis rather than dogmatic assertions of 'irrationality' and 'incommensurability'. Therefore, it is hard to reply to M-G's apparent incredulity. As it is also explained how it is possible that we need not "desire some [of our own] desires" (if you desire to smoke, you might also have a second-order desire not to have that desire) or "value some [of our own] values" (if you value your appearance to a narcissistic degree, you might also have a second-order value not to have that value) and as it is not explained why S-G finds this "perplexing", it does not seem useful to add anything.

M-G asserts that the "definition"-abstract theory, in fact - of libertarian interpersonal liberty as, in short form, the absence of (initiated or proactively) imposed costs "attracts obvious counterexamples". But the only suggestion of an offered counterexample is the confused question, "is inherited debt really a lack of liberty?" If my father's debt were to be simply imposed on me (rather than merely to be taken out of his estate before any remaining inheritance is passed on), then that would seem to be a restriction on my liberty. If I willingly took on his business knowing it to be in debt, then that would not. Where is the problem?

M-G does not grasp why or how EFL uses a non-moralised theory of liberty (as the abstraction that is presupposed by libertarianism). It is because the book is defending the objective thesis that (libertarian) liberty does not systematically clash with overall welfare or private-property anarchy: an extreme version of "the classical liberal compatibility thesis", as EFL calls it. This is explained clearly in the introductory chapter and referred back to throughout. Morals are an irrelevant distraction from this objective claim. That is why it does not discuss "say, absence of illegitimately imposed cost?" (as M-G asks). As all this is thoroughly explained it is foolish to ask, "Why seek to maximize it? Why even care if it is compatible with welfare?" and state that "No answers are given." It is foolish in the sense not only that answers are given, but also in the sense that outside of the book the compatibility of these things is obviously of great moral and practical consequence (as is also explained in the introductory chapter).

${ }^{1}$ Political Studies (September 2001, p. 786). 
M-G also finds it a "perplexing claim that "what I have control over I own in a de facto sense"" and asks, "Is, even de facto, ownership ever just a question of control?" The answer is yes. ${ }^{2}$ If M-G had a counterargument to the given explanation, then it would be possible to reply to it. And again, "Can one add, as Lester does, that if there is liberty, then there is ownership [...]?" Yes, one can add that. And one will be right. And I add it with arguments that M-G fails to criticise. ${ }^{3} \mathrm{M}-\mathrm{G}$ rightly states that $E F L$ "cannot appeal to a normative (i.e. moralized) requirement to avoid imposing costs on others, to avoid lessening liberty, by not taking what they have made." But why would EFL attempt to do that? It is explaining the objective consequences of, or what is entailed by, applying an abstract libertarian theory of liberty and its maximisation. Bringing morals into the argument would be as irrelevant as applying them to mathematics or logic.

As EFL is critical rationalist (M-G offers no evidence of having read or understood even the short introductory chapter), it does not have any "foundational premises", so "the value of reading this book" can hardly depend on them. This "value of reading this book" remark also appears to suggest that we should not value reading books with which we have fundamental disagreements. That is a very foolish position for any would-be thinker. On the contrary, we should seek out such books as being of especial value in challenging our theories, and then we should read them carefully to make sure what they are actually arguing and then attempt to formulate real arguments against them. I fear all this is alien to the current practices exhibited in $\mathrm{M}-\mathrm{G}$.

M-G concludes, "It is also worth remarking that the notion of duty, or responsibility, does not even feature in the index." Not only is this not worth remarking it is clear evidence that M-G does not even grasp the nature of the basic non-normative thesis that the book is defending. A one-page explanation of the basic theory can now be found here.

Even as a first-year undergraduate review, this is an F.

J C Lester, July 2002 (Edited August 2020)

\footnotetext{
${ }^{2}$ If I have ultimate control over something, then I have what is in effect (or de facto) ownership even if the institution of property does not yet exist. But to avoid confusion, I have learnt to leave property unmentioned in the state-of-nature application of the abstract theory.

${ }^{3}$ If interpersonal liberty is hypothesised as maximally to be applied to a state of nature, then one has ultimate control over oneself and any unused resources that one starts to use. The institution of property is only then contingently entailed as a practical way of defending such liberty.
} 